\title{
Electrical stimulation of the auditory brain stem structure in deafened adults
}

\author{
LAURIE S. EISENBERG, M.A.;* ALBERT A. MALTAN; FRANCO PORTILLO; J. PHIL \\ MOBLEY, M.S.E.E.; WILLIAM F. HOUSE, M.D. \\ House Ear Institute, 256 South Lake Street, Los Angeles, California, 90057**
}

\begin{abstract}
Electrical stimulation of the cochlear nuclear complex in the brain stem was first accomplished in a female adult deafened by bilateral acoustic tumors. The central electroauditory prosthesis (CEP) was surgically placed at the time of the second tumor removal. The patient has now been receiving electrical stimulation for 5 years. Six more adults have received the CEP at the time of tumor surgery. Clinical results indicate fluctuations in electrical measurements over time, particularly in the first weeks following surgery. Patients are able to sustain tone perception for one minute at all frequencies tested. Auditory discrimination test results reveal abovechance performance on suprasegmental measures, similar to scores achieved by cochlear implant users. No serious complications have occurred to date.
\end{abstract}

DOI $10.1682 / J R R D .1987 .07 .0009$

\section{INTRODUCTION}

In recent years, cochlear implantation has become clinically feasible in the rehabilitative management of the profoundly deaf. Some individuals, however, are not able to benefit from cochlear electrical stimulation due to the nature of their pathology, such as auditory nerves severed during either acoustic tumor surgery or temporal bone fracture. For these individuals, electrical stimulation at higher centers in the central auditory nervous system may partially restore the sensation of hearing.

\footnotetext{
* Presently at City University of New York Graduate Center, New York, New York

** The House Ear Institute is an affiliate of the University of Southern California School of Medicine
}

Electrical stimulation of the cochlear nuclear complex in the brain stem was first accomplished at the House Ear Institute (HEI) in a female adult deafened by bilateral acoustic tumors (4). The central electroauditory prosthesis (CEP) was surgically placed in 1979 during the second tumor removal. The device stopped working about 2 months later due to breakage of the electrode and was replaced with a new system in 1981 . The patient has now been receiving electrical stimulation for 5 years. To our knowledge, this person is the first human to receive chronic electrical stimulation of the brain stem. Since that time, six more adults have received the CEP during tumor surgery.

Because of the complexities in delivering an electrical stimulus to the brain stem area, specialists from many different disciplines are involved, including neurotology, neurosurgery, neuroanatomy, biomedical engineering, electrophysiology, psychoacoustics, audiology, and psychology. A clinical trials program is being carried out under an FDA approved Investigational Device Exemption (IDE). This paper describes the CEP system, the clinical program for patient testing, device fitting, rehabilitation, followup testing by an engineering/audiology team, and the results to date.

\section{DESCRIPTION OF DEVICE}

The CEP consists of a bipolar surface electrode 9 assembly. The electrode array is composed of two 
platinum electrode plates mounted on a woven Dacron mesh pad (Figure 1). Research by Bullara et al. (3) has shown Dacron mesh to be a superior carrier of electrodes for neural stimulation. The dimensions of the CEP Dacron mesh pad are 2.5 $\mathrm{mm} \times 8.5 \mathrm{~mm}$. Each of the platinum electrode plates is $0.75 \mathrm{~mm} \times 2.5 \mathrm{~mm} \times 0.025 \mathrm{~mm}$. The two electrode plates are separated by $4.25 \mathrm{~mm}$. The plates are insulated with varnish (Epoxilite), except for the active surface.

Platinum electrode leads are welded to the plates and wrapped around 7-0 nonabsorbable monofilament nylon sutures, forming two spiral cables that are coated with silicone (Silastic Type A). The sutures allow the electrode wire to tolerate longitudinal stress that may occur with movement of the brain. The spiral cables are connected to a Pyrolite carbon percutaneous pedestal (Carbomedics), or plug, that houses the electrode connector (ITT Cannon) (Figure 2). Also attached to the pedestal in the present device is a $3-\mathrm{cm}$ bare platinum wire ( 0.008 inch in diameter) that provides a reference electrode for monopolar stimulation of either plate on the bipolar electrode array. (Three patients have received this newer design so that additional stimulation strategies can be tested more easily.)

The bipolar electrode array is placed on the cochlear nuclear complex after removal of the tumor. The cochlear nuclear complex lies along the dorsolateral surface of the brain stem at the pontomedullary junction. The area of the cochlear nuclear complex can be located through the translabyrinthine surgical approach (9). After the tumor is removed, the stump of the eighth nerve is identified and followed to the brain stem and the lateral recess of the fourth ventricle. The landmarks used for placement of the electrode array include the flocculus, the choroid plexus, and the tenia of the choroid plexus (13). The electrode array is placed over the cochlear nuclear complex. A small piece of abdominal fat is placed over the electrode to hold it in place. The remote-reference electrode wire is placed in the temporalis muscle. The electrode wires are brought out through the mastoid cavity where

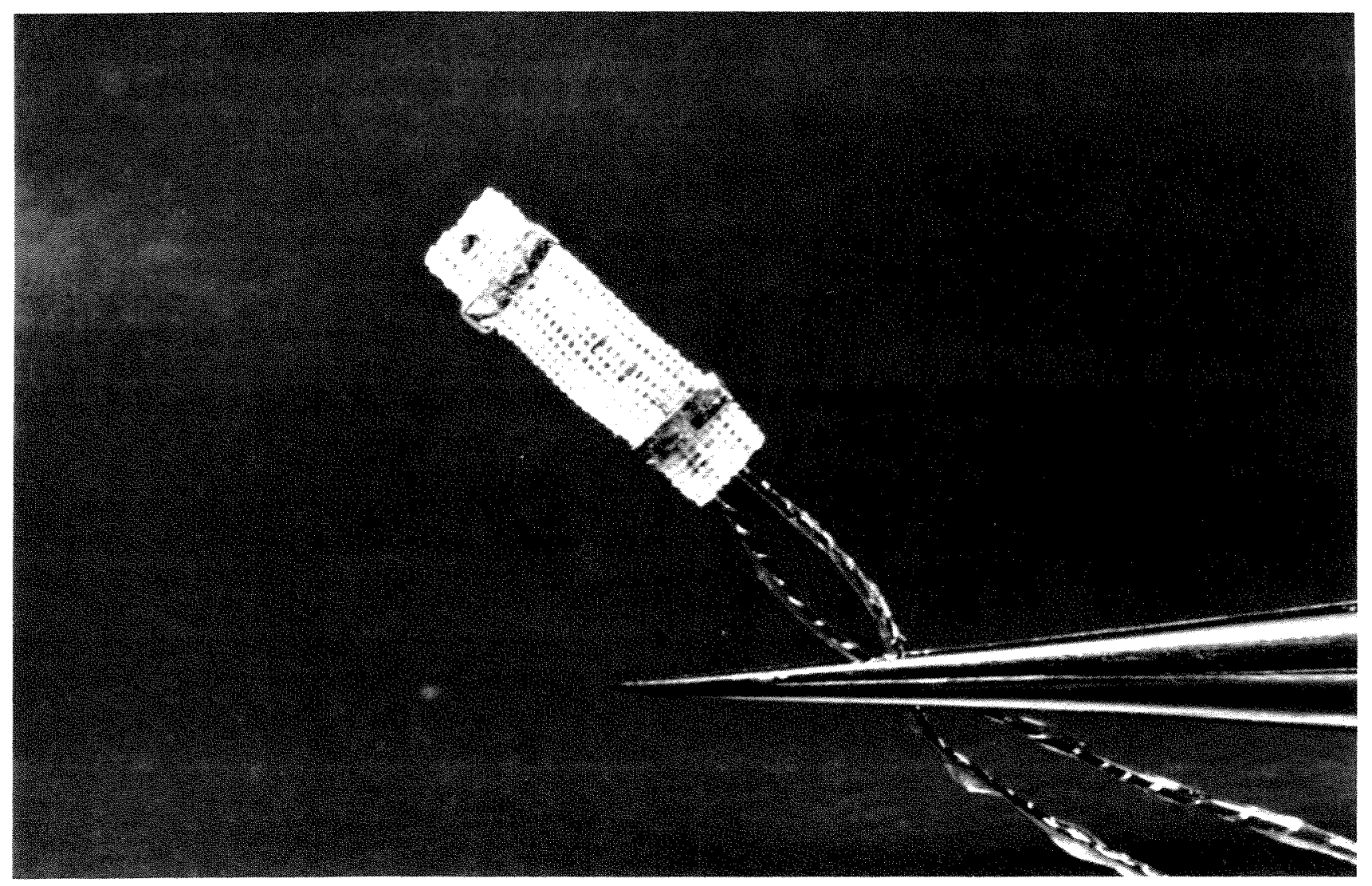

Figure 1.

CEP bipolar surface electrode. 
the percutaneous pedestal is secured posterior to the mastoid bone and then placed through the skin above the ear.

The block diagram in Figure 3 illustrates the signal processing scheme known as the $3 \mathrm{M} /$ House design; the electrical analog of the acoustic signal amplitude modulates a $16-\mathrm{kHz}$ sinusoidal carrier wave (8). The level of the $16-\mathrm{kHz}$ carrier is set to be one-tenth of the fully modulated signal, which is the uncomfortable loudness level (ULL) of the patient. In one patient, a Bosch T-80 hearing aid was used to provide a baseband signal during an early phase of the program (Figure 4).

\section{DESCRIPTION OF CLINICAL TRIALS PROGRAM}

Based on experience with the first patient, a clinical trials program for gathering ongoing safety and efficacy information was developed. This program involves careful monitoring of the patient over time. Testing of the electrode begins as early as the second postoperative day while the patient is still in the intensive care unit; this testing continues throughout the hospital stay, under medical supervision. Two to three months later the signal proces- sor is fitted, and the patient goes through a Basic Guidance orientation period similar to the program developed for cochlear implant patients (6). Following Basic Guidance, the patient is scheduled every 3 months for testing during the next year, and every 6 months thereafter.

Clinical data being collected for the CEP project include both electrical and audiological measures. Electrical thresholds and uncomfortable loudness levels for $250-\mathrm{Hz}-4 \mathrm{kHz}$ and $16-\mathrm{kHz}$ sinusoids are obtained. Current $(\mu \mathrm{A})$, voltage $(\mathrm{mV})$, and charge density $\left(\mu \mathrm{C} / \mathrm{cm}^{2}\right.$ phase) are measured. Tone decay for $250-\mathrm{Hz}-4-\mathrm{kHz}$ and $16 \mathrm{kHz}$ is also tested.

Audiological sound-field measures include thresholds for $250-\mathrm{Hz}-4-\mathrm{kHz}$ warble-tones and speech detection and uncomfortable loudness levels. Discrimination is assessed using the MonosyllableTrochee-Spondee (MTS) test (7), the HEI Environmental Sounds test (14), the Speech Pattern Contrast (SPAC) test (1), and the Minimal Auditory Capabilities (MAC) battery (11). The MTS and HEI Environmental Sounds tests are both closed-set (i.e., multiple-choice) tests that have been widely used with adult $3 \mathrm{M} /$ House cochlear implant patients. The SPAC measures perception of a number of suprasegmental and segmental aspects of speech. The MAC contains a number of both closed- and openset subtests of speech discrimination.

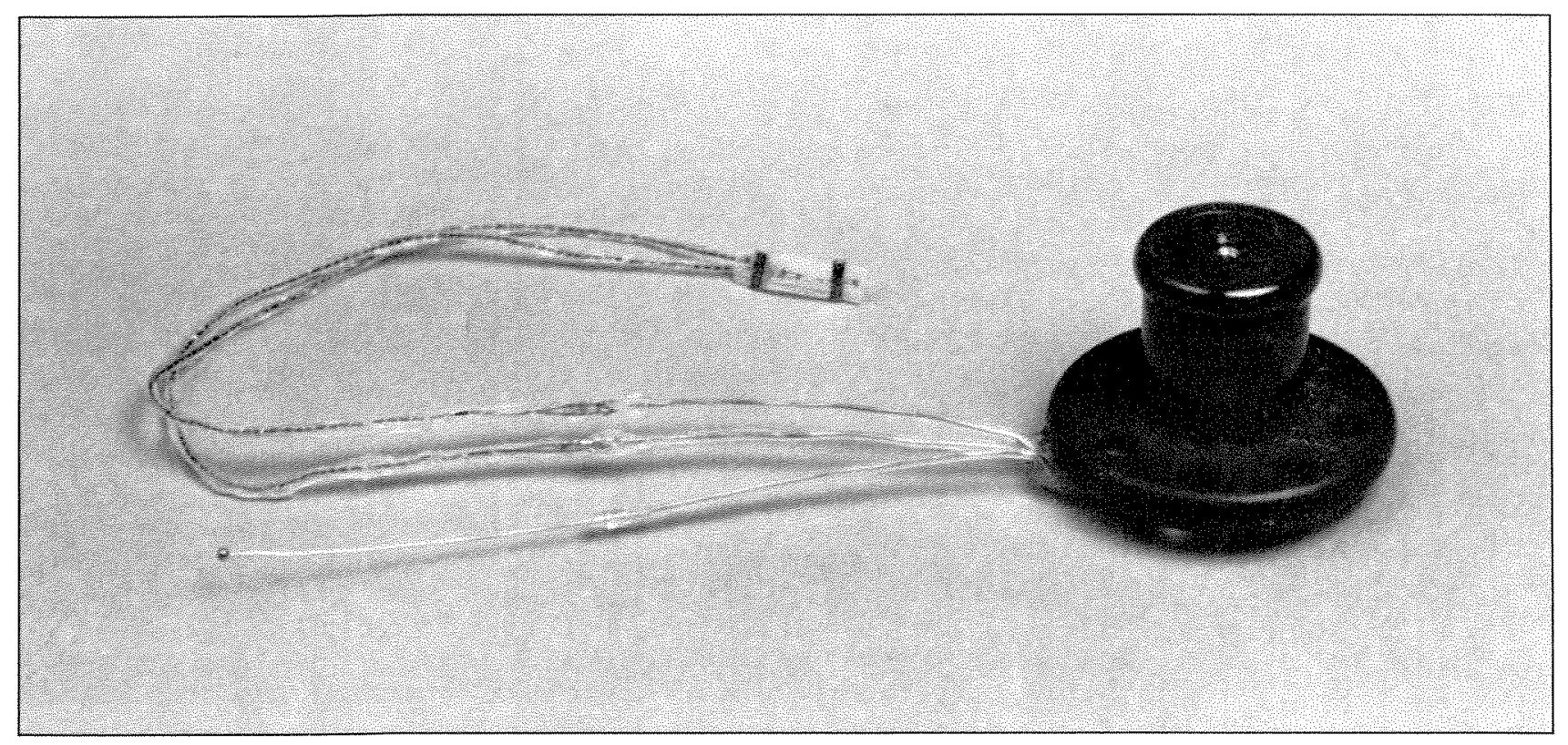

Figure 2.

CEP electrode array consisting of electrode, cables, remote reference, and percutaneous pedestal. 


\section{CENTRAL ELECTROAUDITORY PROSTHESIS}

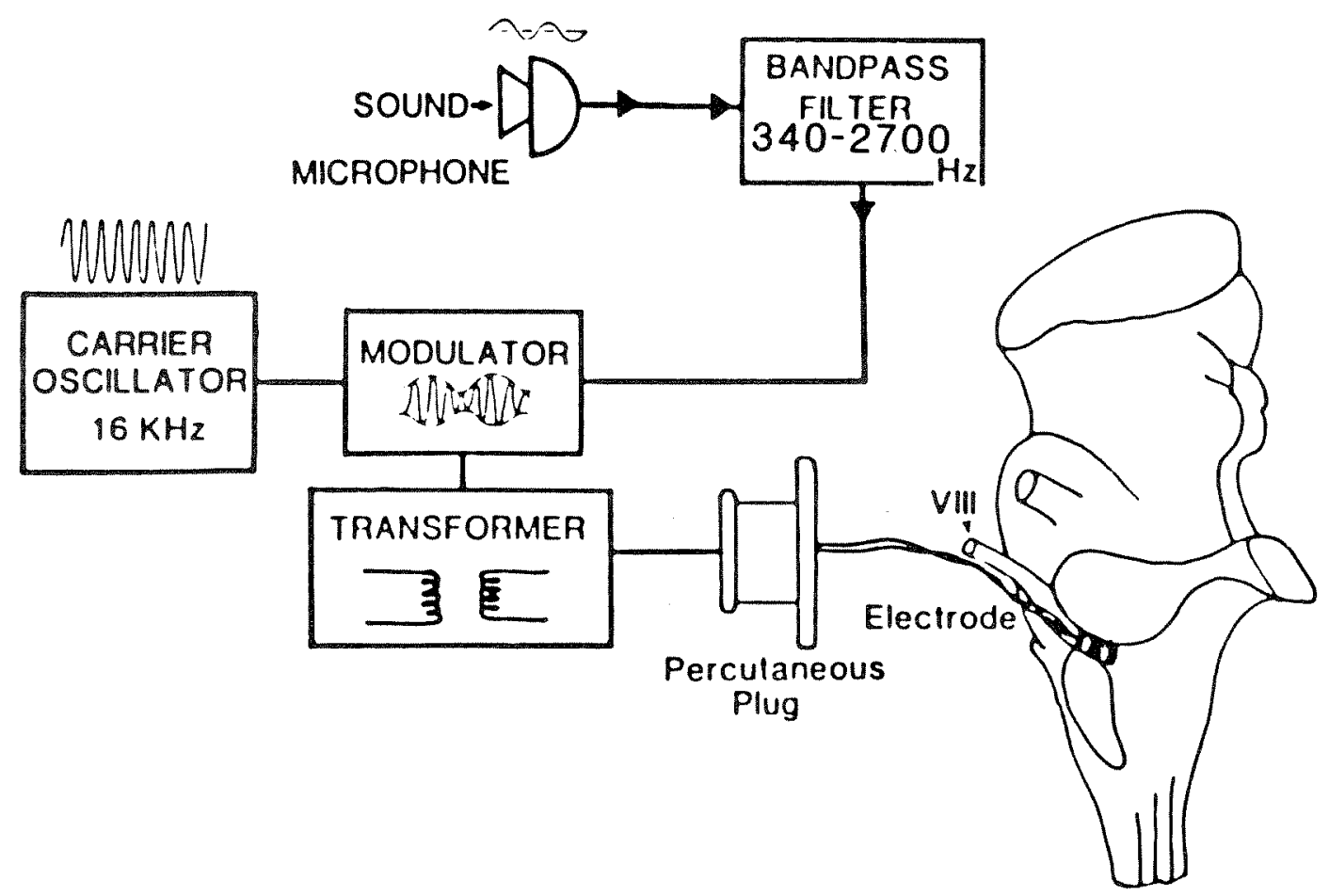

Figure 3.

Block diagram of the CEP and the $3 \mathrm{M} /$ House signal processing scheme.

\section{Electrical Test Considerations}

A block diagram of the CEP patient test setup is shown (Figure 5). It consists of a variable signal generator, logic circuitry to control stimulus duration and rise/fall time, amplifier, and isolation transformer for patient safety. The rms voltage and current are monitored at the patient interface box with battery-powered multimeters and a transformer-isolated high impedance input oscilloscope.

Signal trains of sinusoidal stimuli used for electrical thresholds and uncomfortable loudness levels (ULL) are 2 seconds in duration with rise and fall times of $50 \mathrm{~ms}$. A continuous stimulus of 1 minute is used for tone-decay testing. Tone-decay testing is presented in voltage levels as a percentage of the dynamic range. (Current levels are also monitored during application of the stimulus.)

In addition to standard testing of the bipolar electrode, monopolar testing of each individual electrode plate can be performed. Before development of the presently used electrode assembly with remote reference, a subdermal needle electrode was temporarily inserted below the tragus and in front of the ear lobe to act as the remote indifferent electrode.

\section{Audiological Test Considerations}

Testing is performed in a single-walled, soundtreated booth, meeting American National Standard Institute (ANSI 1969) standards. Patients are tested in the sound field, seated 1 meter from the loudspeaker, with their signal processors adjusted to a most comfortable loudness level. A miniature electret microphone is in close proximity to the microphone of the signal processor where auditory stimuli are monitored in $\mathrm{dB}$ re $20 \mu \Pi$ a on a sound level meter. Threshold and uncomfortable loudness levels, while measured in $\mathrm{dB}$ SPL, are converted to hearing level (dB HL) (10). All discrimination tests are tape recorded and administered at $70 \mathrm{~dB}$ SPL. 


\section{Baseband stimulator}

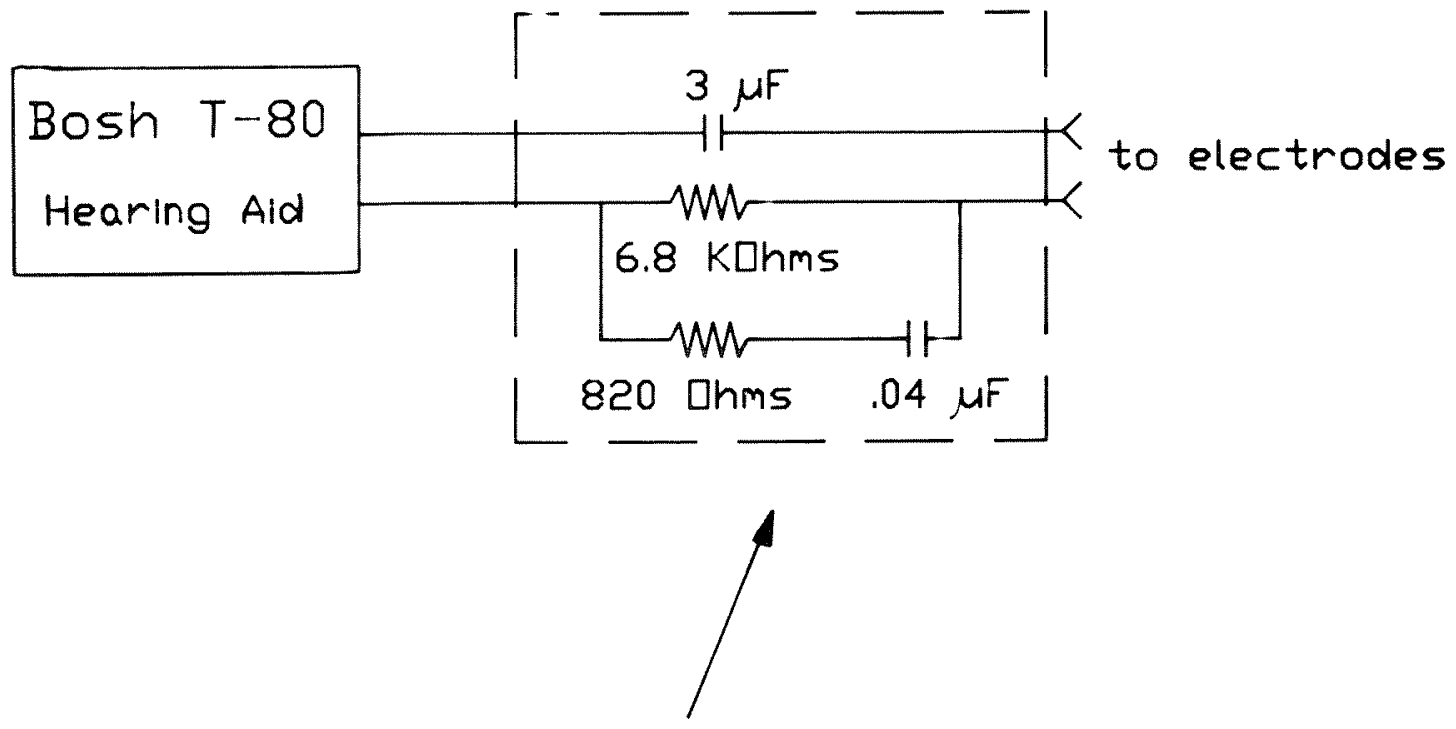

Attenuator/filter to balance output to a most

comfortable level in patient's dynamic range

Figure 4.

Diagram of the baseband processing scheme used with patient MD.

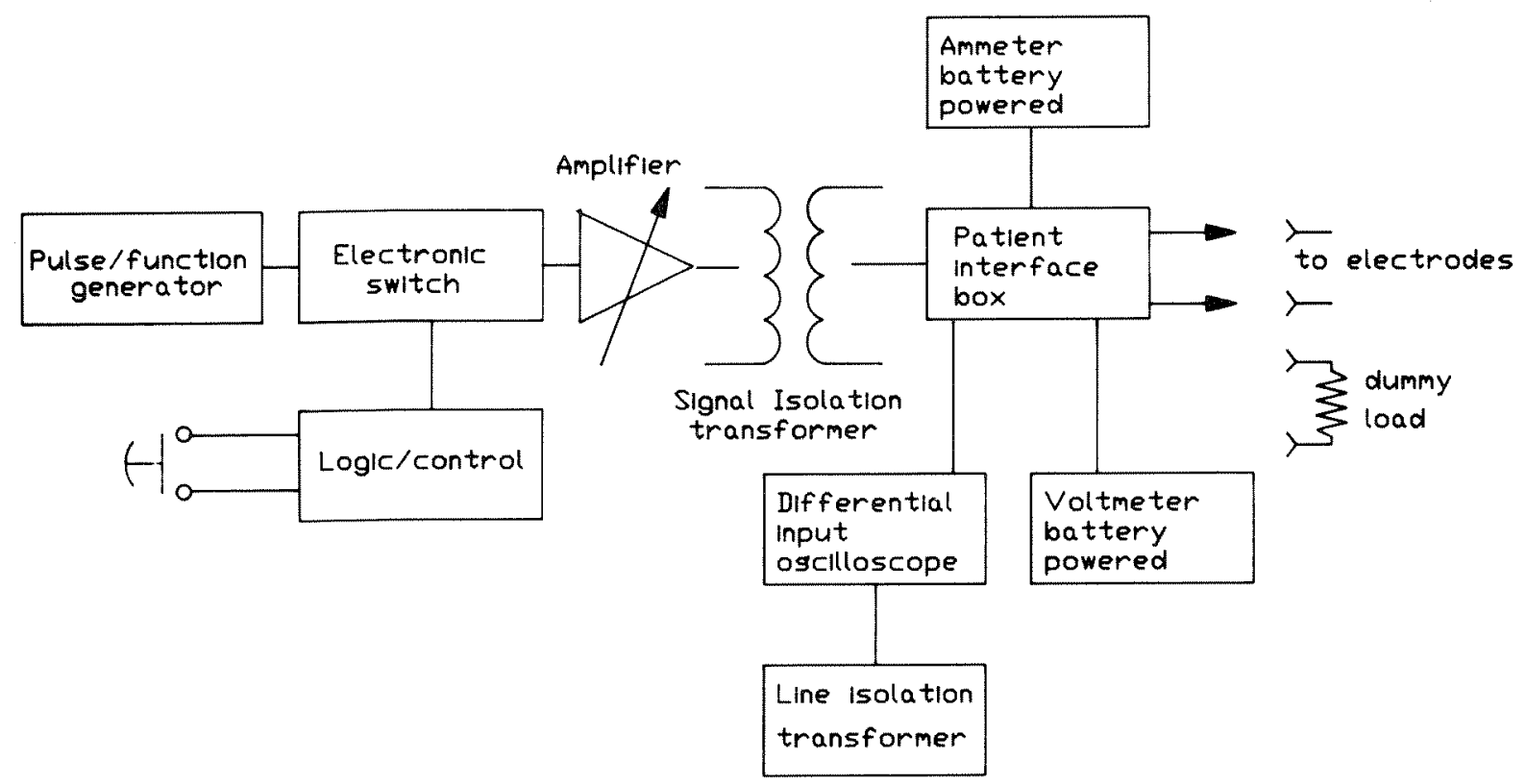

Figure 5.

Block diagram of CEP patient test setup. 
Journal of Rehabilitation Research and Development Vol. 24 No. 3 Summer 1987

\section{DESCRIPTION OF PATIENTS}

Data on the seven patients who have received the CEP are presented in Table 1. There are four females and three males ranging from 19 to 57 years old, with a mean age of 40.7 years. All were diagnosed as having bilateral acoustic tumors. Their preoperative discrimination scores ranged from 0 percent to 60 percent; tumor removal resulted in total hearing loss. The CEP was placed in six patients during the second tumor removal. Patient SS received the CEP during the first tumor surgery and has not yet undergone surgery for the second tumor.

Six of the seven patients have been successfully stimulated with the CEP. Patient MW underwent surgical removal of the device 3 days after it was inserted, due to discontinuity in the current path of the implant system. Infection in four patients caused the percutaneous pedestal to be rejected at various intervals following the onset of stimulation. For example, MD had the pedestal for 4 years, while DS had it for only 6 months. The pedestals were surgically removed and the areas allowed to heal. Patient MD (originally using a baseband processing scheme) was implanted with a transcutaneous magnetic system compatible with the amplitude-modulated $16-\mathrm{kHz}$ processor. The systems in patients JB, $\mathrm{SS}$, and DS are being changed to transcutaneous magnetic induction coupling systems. (The data presented, however, are from the percutaneous systems.) With the exception of patients MD and HR, followup times are less than 1 year.

\section{RESULTS}

\section{Electrical Results}

Impedance at threshold for $1000 \mathrm{~Hz}$ as a function of time for three representative patients is shown in Figure 6. An increase in impedance during the first weeks after surgery has been observed for all the CEP patients. This increase may be associated with tissue changes surrounding the electrode plates occurring during the postsurgical healing process. Figures 7 and 8 show threshold current and voltage measurements at $1000 \mathrm{~Hz}$ for these same four patients as a function of time.

Threshold and uncomfortable loudness current levels for patient HR over the tested frequency range are plotted in Figure 9. These levels are typical of those obtained across our patient group. The average dynamic range for $C E P$ patients is only about $6 \mathrm{~dB}$. One patient exhibited an average dynamic range as little as $4 \mathrm{~dB}$. The safe stimulation level line in Figure 9 represents a charge density limit of $17 \mu \mathrm{C} / \mathrm{cm}^{2}$ phase across frequencies (see Appendix). ULL is clearly below this limit. No patient to date has required current levels exceeding this for any frequency.

Monopolar testing has been performed on three

Table 1

Central electroauditory prosthesis (CEP) patient status

\begin{tabular}{|c|c|c|c|c|c|}
\hline $\mathbf{S}$ & Sex & $\begin{array}{l}\text { Date(s) } \\
\text { Surgery }\end{array}$ & $\begin{array}{l}\text { Age (yrs) } \\
\text { Surgery }\end{array}$ & $\begin{array}{c}\text { Signal } \\
\text { Processor }\end{array}$ & $\begin{array}{l}\text { Most Recent } \\
\text { Followup }\end{array}$ \\
\hline MD & $\mathrm{F}$ & $\begin{array}{l}5 / 79 \\
3 / 81 \\
6 / 85\end{array}$ & 46 & $\begin{array}{c}\text { AM } \\
\text { Baseband } \\
\text { AM }\end{array}$ & 5 years* \\
\hline MW & M & $8 / 81$ & 37 & - & - \\
\hline HR & $\mathbf{M}$ & $7 / 84$ & 50 & $\mathrm{AM}$ & 1 year \\
\hline JB & F & $\begin{array}{r}1 / 85 \\
12 / 85\end{array}$ & 19 & $\mathrm{AM}$ & 3 months \\
\hline SS & $\mathrm{F}$ & $\begin{array}{r}5 / 85 \\
12 / 85\end{array}$ & 57 & $\mathrm{AM}$ & Basic Guidance \\
\hline DS & $\mathrm{F}$ & $\begin{array}{l}9 / 85 \\
3 / 86\end{array}$ & 33 & $\mathrm{AM}$ & Basic Guidance \\
\hline JH & 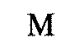 & $3 / 86$ & 43 & - & Postsurgery** \\
\hline
\end{tabular}




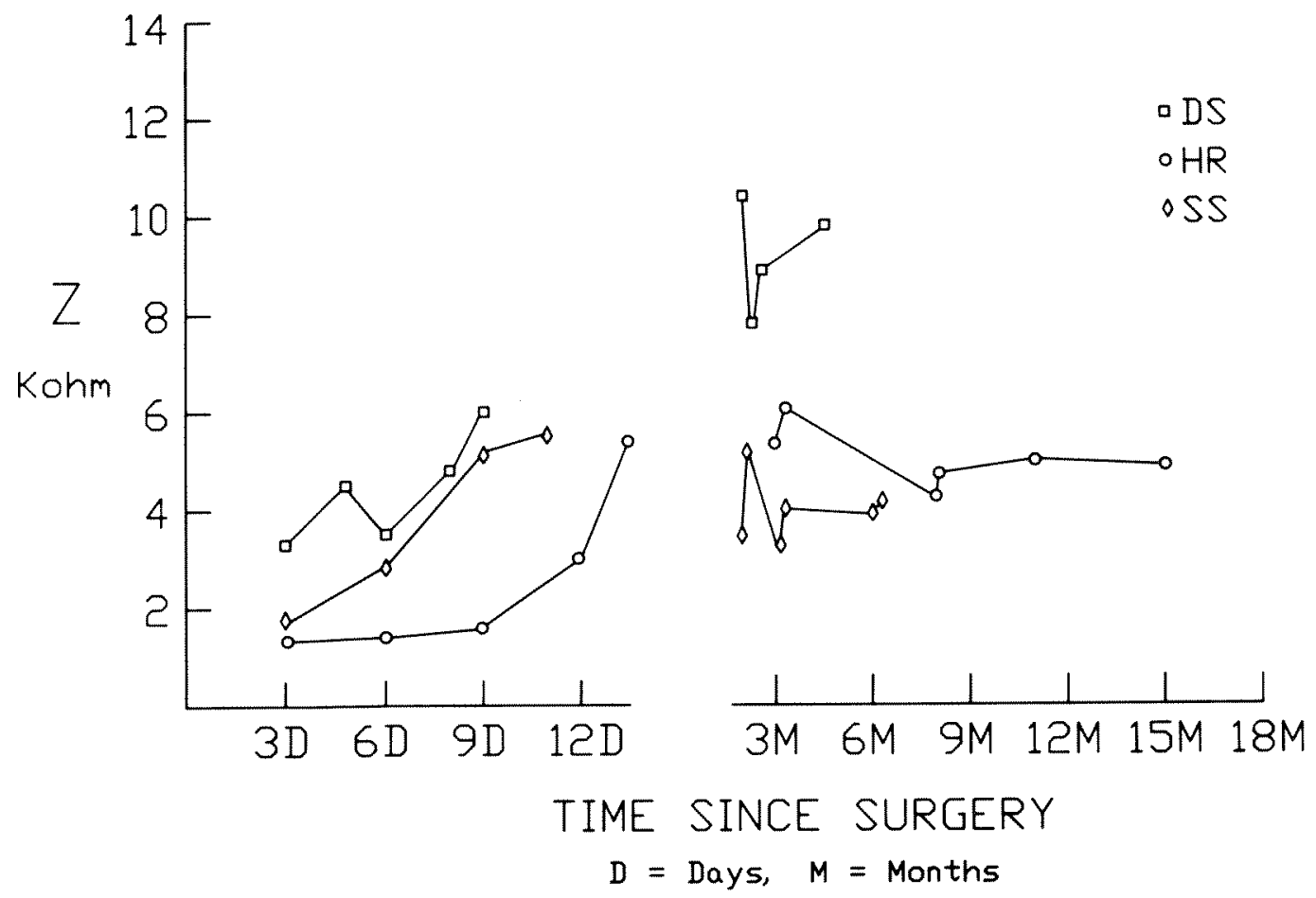

Figure 6.

Impedance at threshold for $1000 \mathrm{~Hz}$ for three patients.

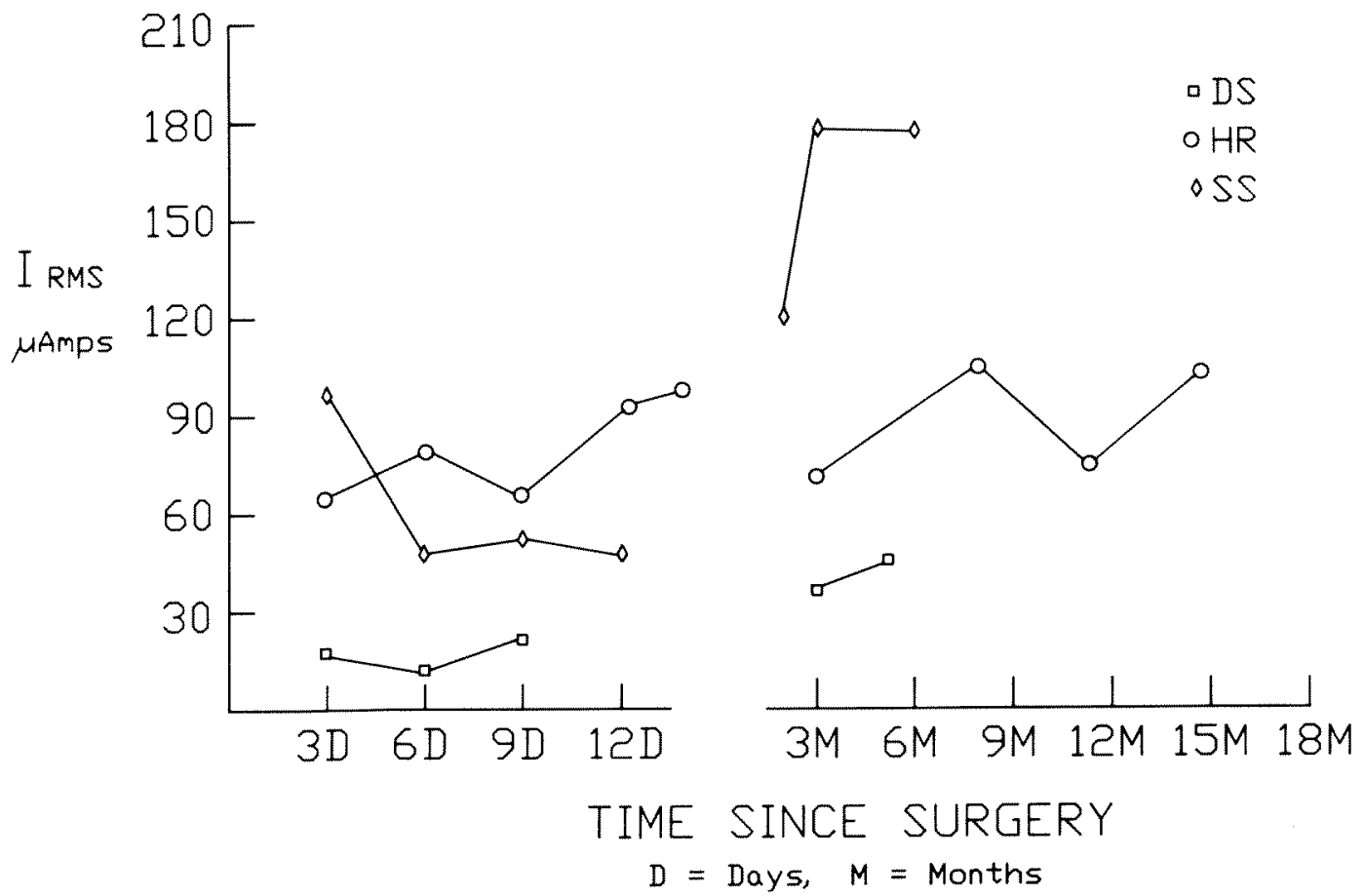

Figure 7.

Current threshold for $1000 \mathrm{~Hz}$ for three patients. 
Journal of Rehabilitation Research and Development Vol. 24 No. 3 Summer 1987

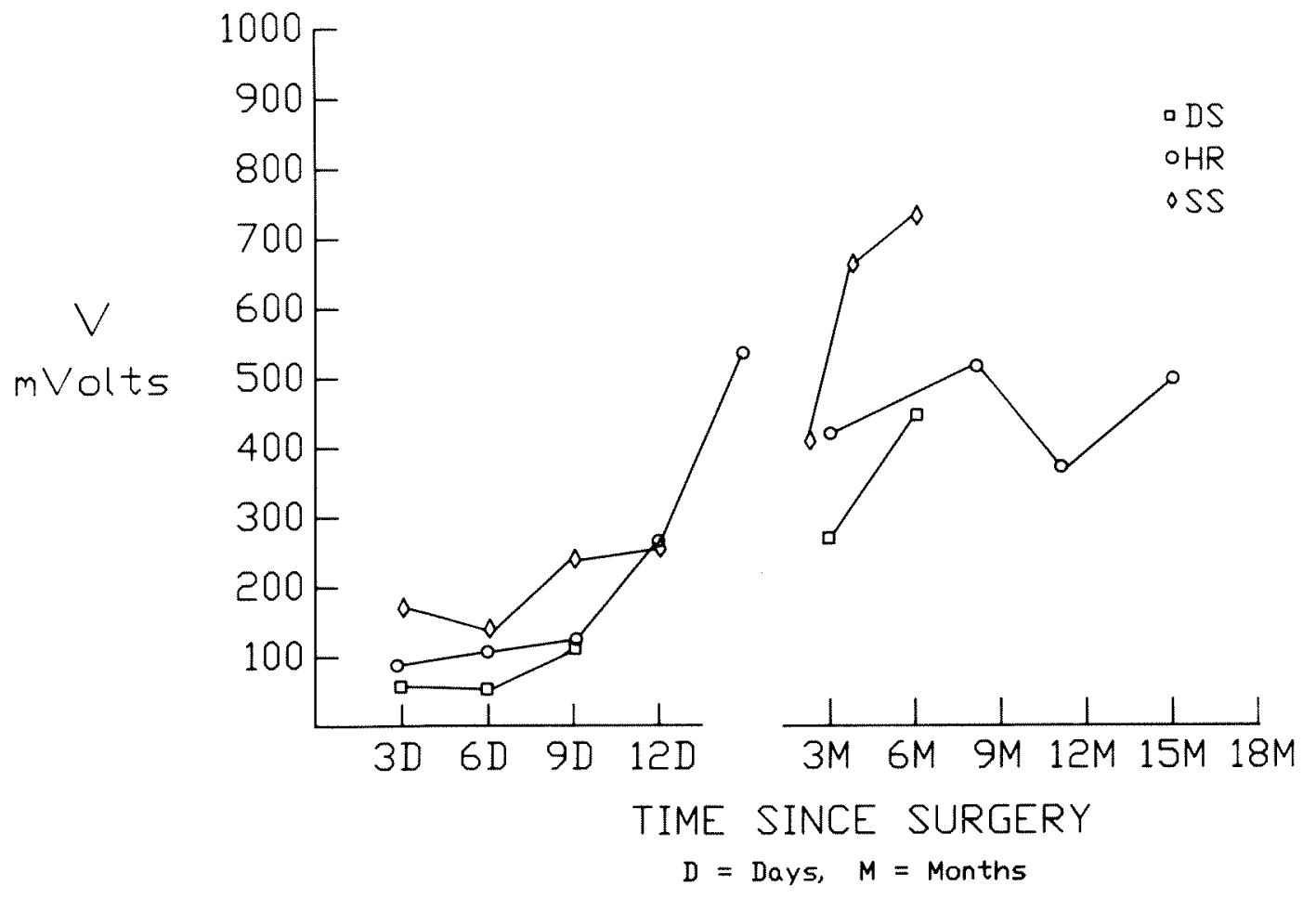

Figure 8.

Threshold voltage for $1000 \mathrm{~Hz}$ for three patients.

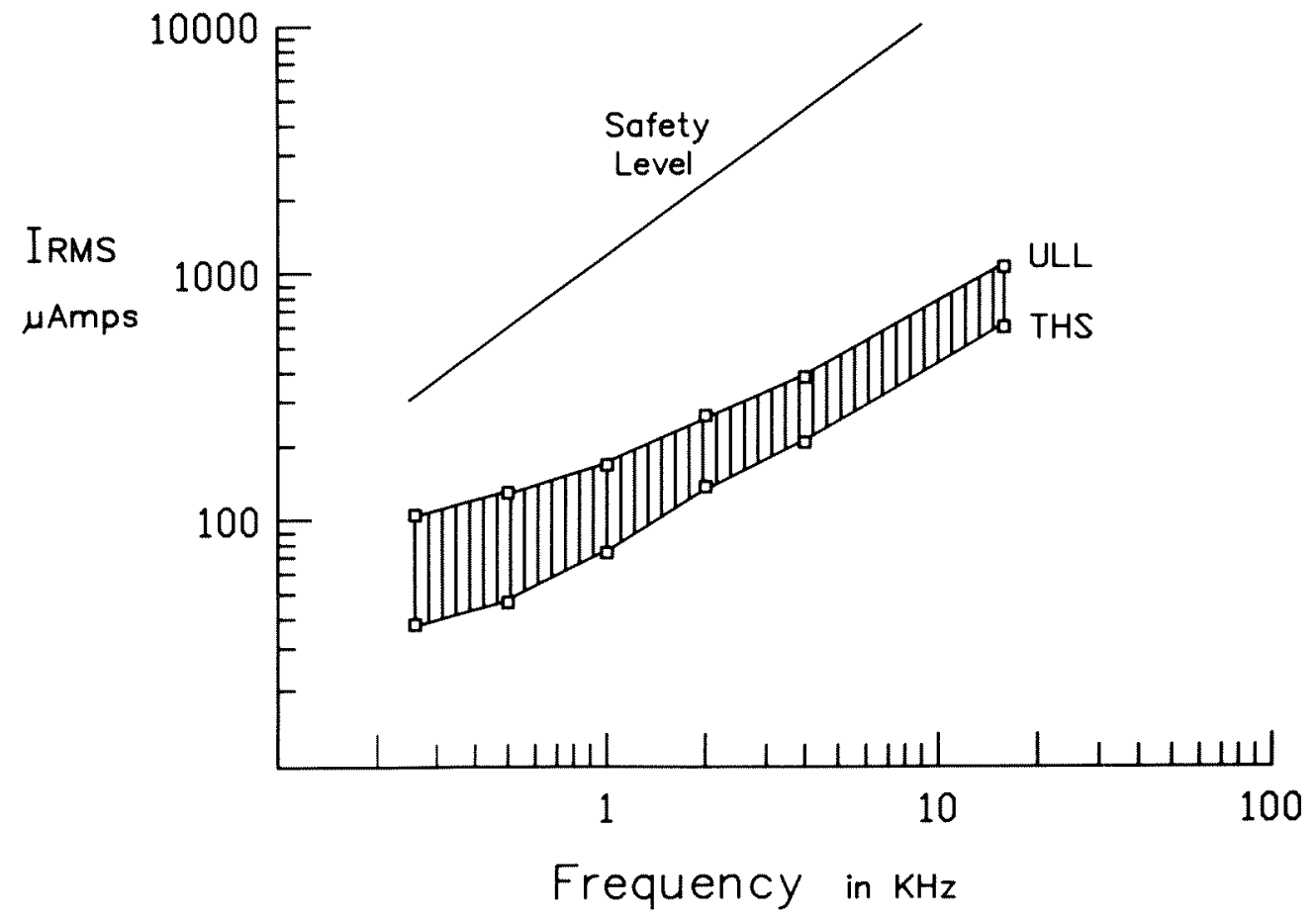

Figure 9.

Frequency response and dynamic range for patient HR. 
patients. Results for patient HR are shown in Figure 10. Considerable differences in dynamic range and current levels are seen for the two individual electrode plates (A and B). On stimulation of plate B, HR exhibited consistent frequency discrimination ability for octave frequencies between 250 and 1000 $\mathrm{Hz}$. Such abilities were not exhibited on stimulation of plate A. With frequency and intensity being balanced for the two plates, HR was able to identify which plate was being stimulated 100 percent of the time. Of the other two patients tested, only one was able to differentiate between the two plates. Monopolar testing was also performed using biphasic pulsatile stimuli (in contrast to sinusoidal) with patient HR. As before, some frequency discrimination ability was exhibited for electrode plate $\mathrm{B}$. The region of the best frequency discrimination ranged from 90 to $250 \mathrm{~Hz}$. No such capability was found for plate $A$.

Tone-decay testing on six patients shows sustained tone perception for 1 minute across the frequency range. In most cases, perception was sustained at low sensation levels-25 percent of the dynamic range. In the early postoperative period, however, the patients required more current to sustain perception at frequencies above $1000 \mathrm{~Hz}$. Impedance remained stable (within 3 percent) during presentation of the continuous electrical stimulus.

\section{Audiological Results}

Audiologic results represent most recent test scores collected on the five patients fitted with signal processors. These results are compared in the following figures and tables with data collected from adults using the $3 \mathrm{M} /$ House single-electrode cochlear implant (CI). Figure 11 presents audiometric detection levels (dB HL) across frequencies. Warble-tone thresholds with the CEP, after acceptable clinical use settings for the processor were obtained, tended to be slightly poorer than those typical of cochlear implant users. However, thresholds were still within the average speech spectrum range (estimated at 6 feet for average conversational speech). The mean speech detection threshold for the CEP group was $44 \mathrm{~dB}$ HL.

Results of auditory discrimination tests indicate that CEP patients, like cochlear implant patients, demonstrate an ability to identify primarily supra-

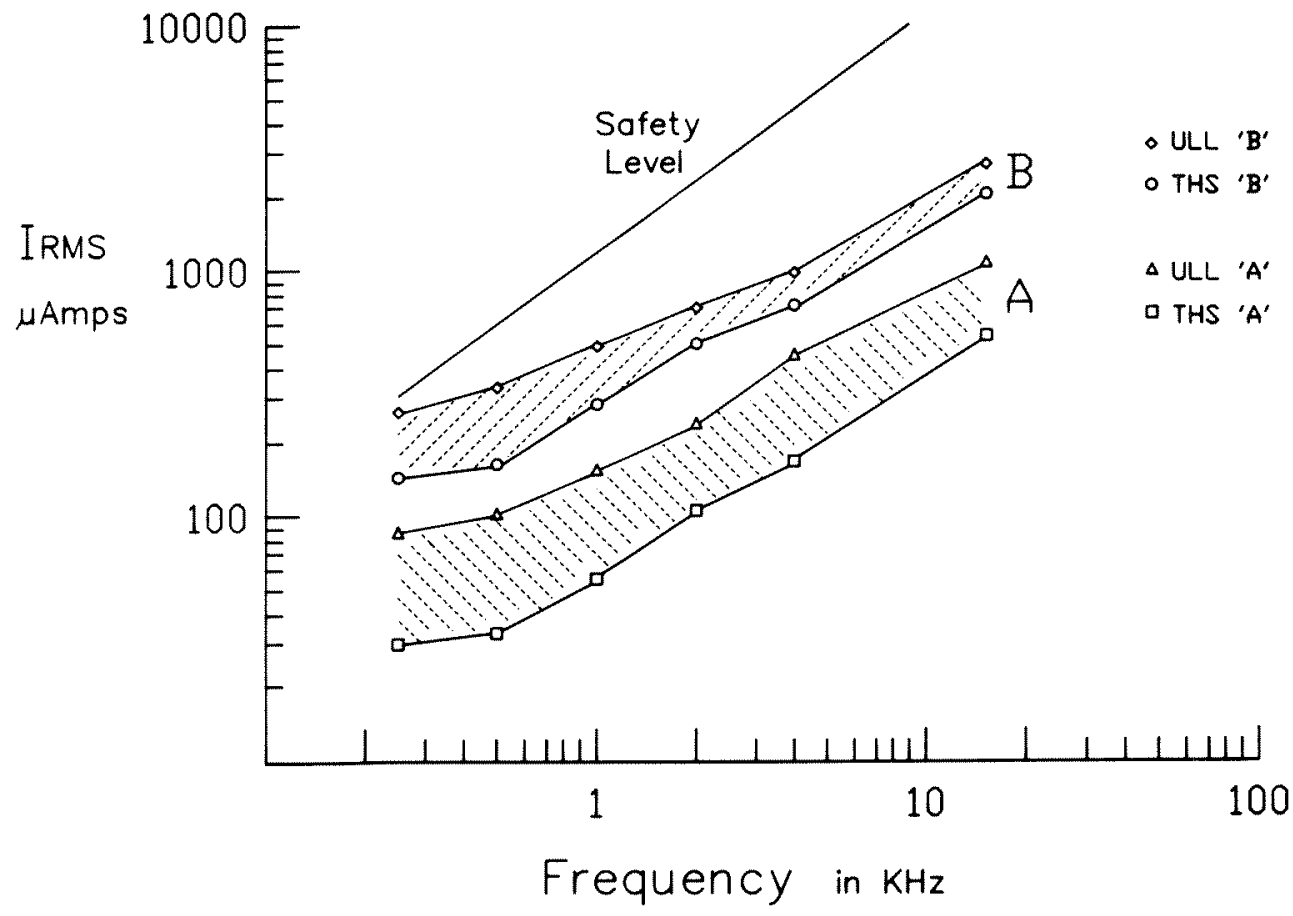

Figure 10.

Threshold (THS) and uncomfortable loudness level (ULL) for electrode plates A and B when tested in a monopolar configuration for patient $H R$. 
Journal of Rehabilitation Research and Development Vol. 24 No. 3 Summer 1987

FREQUENCY IN HERTZ ( $\mathrm{HZ})$

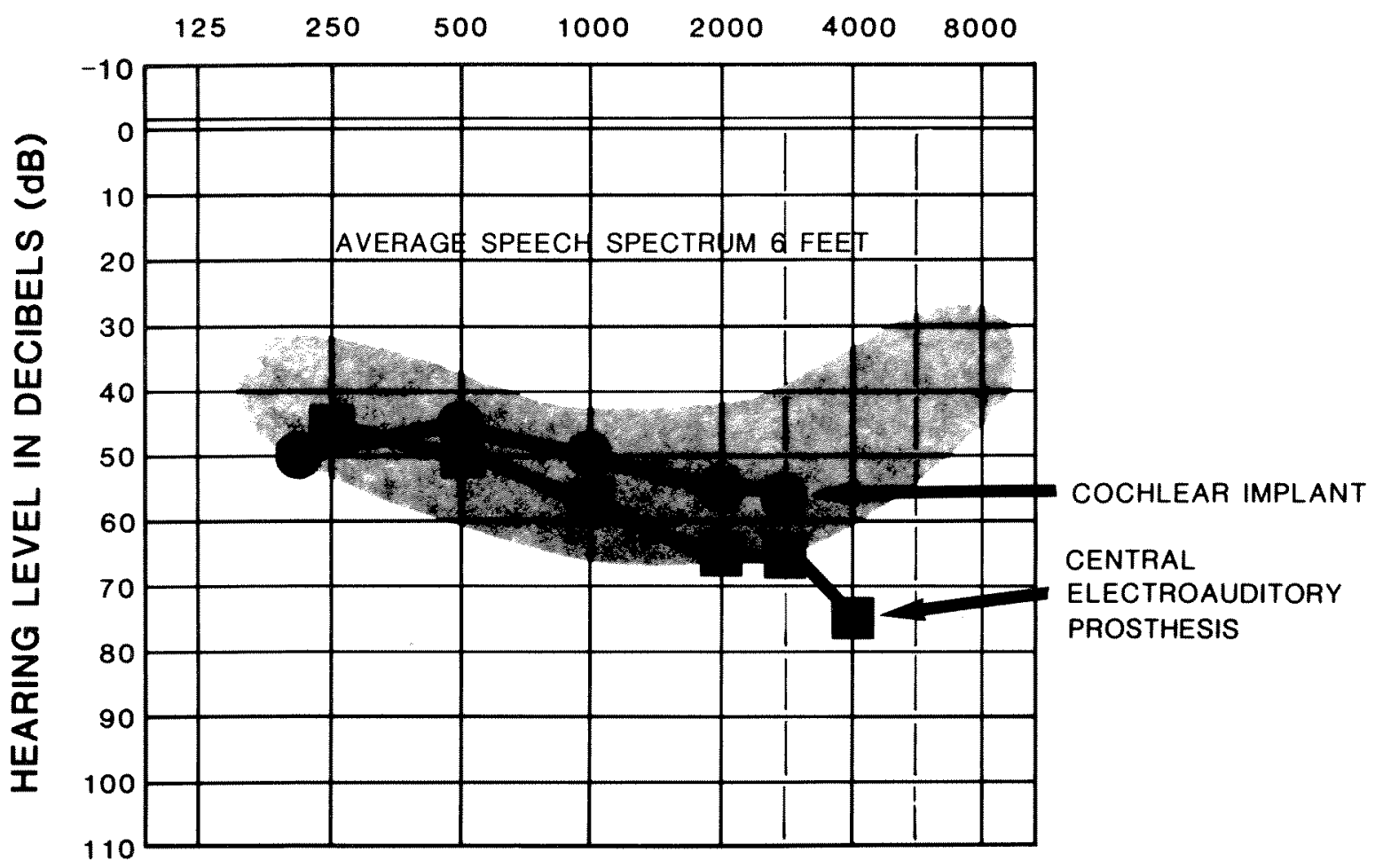

Figure 11.

Mean warble-tone thresholds comparing the CEP to the cochlear implant. Detection levels were measured in dB SPL and converted to Hearing Level using the clinical standards proposed by Morgan et al. (10).

segmental information (rhythm and intonational patterns). Mean word and stress scores on the Monosyllable-Trochee-Spondee test and the Environmental Sounds test are comparable to those from 75 implant users. Both groups scored significantly above chance on these closed-set tests (Table 2).

Results from the Speech Pattern Contrast (SPAC) test indicate that the five CEP patients, as a group, scored above chance on the suprasegmental and consonant voicing subtests (Figure 12). Eight CI users on whom SPAC results are available had similar results (2). The implant group additionally scored above chance on the vowel subtest (Figure 13). The composite score was higher for the $C I$ group (68 percent) than the CEP group (61 percent). Open-set phoneme recognition was poor for both groups (8 percent for CEP and 12 percent for $\mathrm{CI}$ ), although above chance for the $\mathrm{CI}$ subjects.

To date, only the two CEP patients who have completed a 1-year followup have been given the Minimal Auditory Capabilities (MAC) battery. Table
3 shows that patient MD was using the baseband processor, while patient HR was using the amplitude-modulated processor. These scores are compared to those published by Edgerton et al. (5) for 9 to 12 cochlear implant users. The CEP and CI patients scored significantly above chance for many of the same closed-set subtests. They had similar scores for the visual enhancement subtest, which demonstrates lipreading improvement when audition is added. Scores on the open-set everyday sounds

\section{Table 2}

Mean Monosyllable-Trochee-Spondee test and Environmental Sounds test scores for cochlear implant (CI) and CEP patients

\begin{tabular}{lccc}
\hline \multicolumn{1}{c}{ Test } & Chance & $\begin{array}{c}\text { CI } \\
(\mathbf{N = 7 5 )}\end{array}$ & $\begin{array}{c}\text { CEP } \\
(\mathbf{N = 5})\end{array}$ \\
\hline MTS Word & $8 \%$ & $25 \%$ & $36 \%$ \\
MTS Stress & $33 \%$ & $67 \%$ & $78 \%$ \\
Environmental Sounds & $20 \%$ & $45 \%$ & $42 \%$ \\
\hline
\end{tabular}




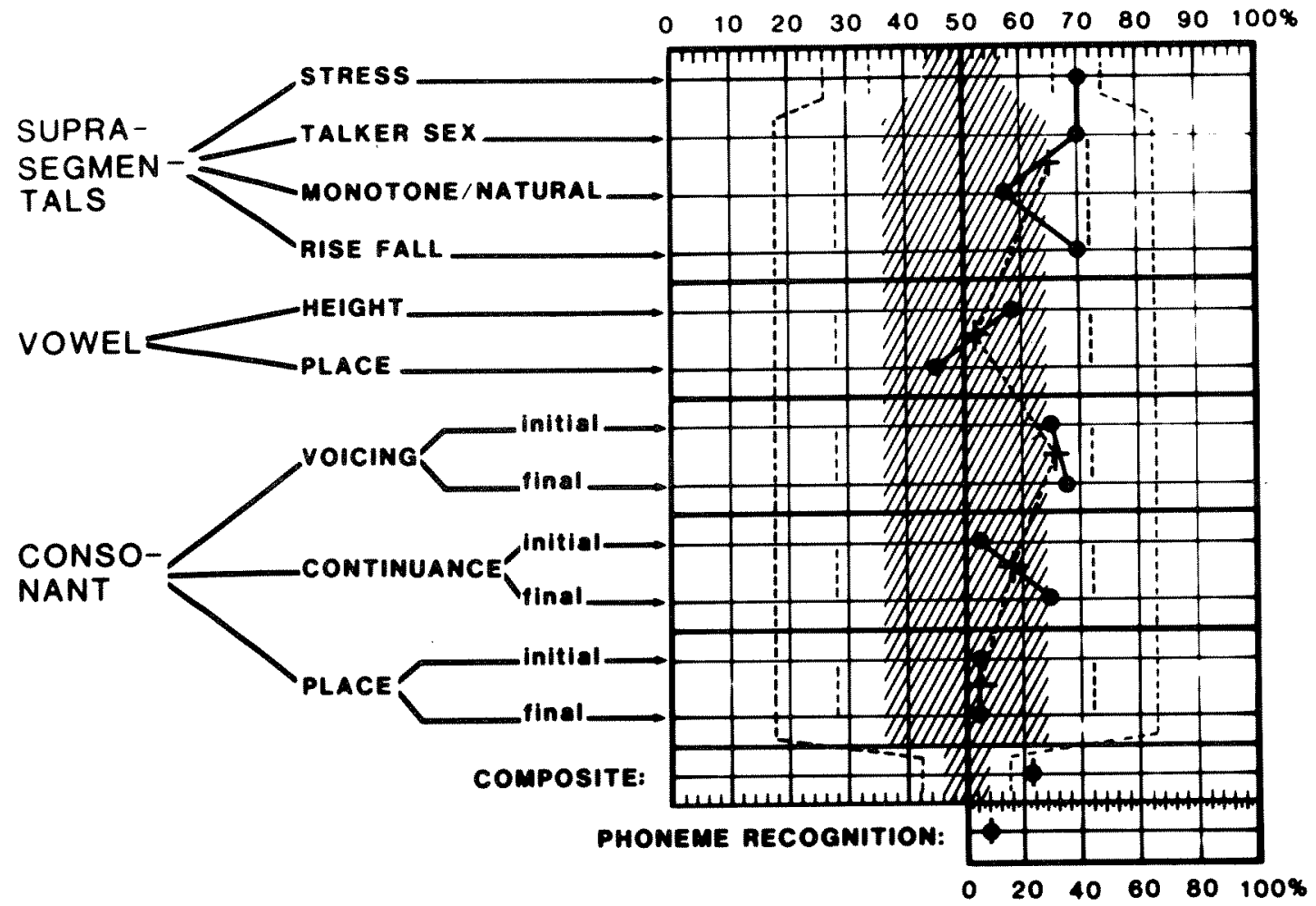

Figure 12.

Mean Speech Pattern Contrast test scores for five CEP patients. The shaded area represents chance performance. Dots represent individual subtest mean scores; plus signs represent the combination of two subtests.

subtest were also similar. Both implant and CEP patients scored very poorly on the open-set word and sentence-tests. Scores ranged only from 0 to 8 percent and are not shown in Table 3.

\section{Subjective Responses}

CEP users have described the auditory perceptions as monotone, muffled, low-pitched, or sounding like static. The patients have tended to be disappointed initially with the CEP. This is understandable when one considers the substantial amount of hearing some patients had before tumor surgery. Patients have reported that the CEP aids in lipreading and in monitoring the voice. The CEP has had no apparent effect on tinnitus, balance, or dizziness.

\section{DISCUSSION}

Initial results with the CEP in six patients indicate that performance is similar to that obtained by patients using the $3 \mathrm{M} /$ House cochlear implant. That
Table 3

Minimal Auditory Capabilities battery percentage scores for cochlear implant patients and two CEP patients; one using a baseband processing scheme and one using the $3 \mathrm{M} /$ House $16 \mathrm{KHz}$ AM processing scheme.

\begin{tabular}{|c|c|c|c|}
\hline Subtest & $\begin{array}{l}\text { Cochlear } \\
\text { Implant } \\
\mathrm{N}=9-12\end{array}$ & $\begin{array}{l}\text { Cent } \\
\text { Electroat } \\
\text { Prosth } \\
\text { MD } \\
\text { (Baseband) }\end{array}$ & $\begin{array}{l}\text { ral } \\
\text { aditory } \\
\text { hesis } \\
\text { HR (AM) }\end{array}$ \\
\hline Question/Statement & $65^{*}$ & 55 & $75 *$ \\
\hline Vowel & 29 & 17 & 20 \\
\hline Noise/Voice & $70^{*}$ & $78^{*}$ & $78^{*}$ \\
\hline Accent & $55^{*}$ & $55^{*}$ & 35 \\
\hline Initial Consonant & $37 *$ & 19 & 30 \\
\hline Spondee (Same/Different) & $80^{*}$ & $70^{*}$ & $85^{*}$ \\
\hline Four Choice Spondee & $55^{*}$ & $50^{*}$ & $50^{*}$ \\
\hline $\begin{array}{l}\text { Final Consonant } \\
\qquad * \mathrm{p}<.05\end{array}$ & $52 *$ & $44^{*}$ & $54 *$ \\
\hline Visual Enhancement & 24 & 19 & 22 \\
\hline Everyday Sounds & 40 & 47 & 33 \\
\hline
\end{tabular}


Journal of Rehabilitation Research and Development Vol. 24 No. 3 Summer 1987

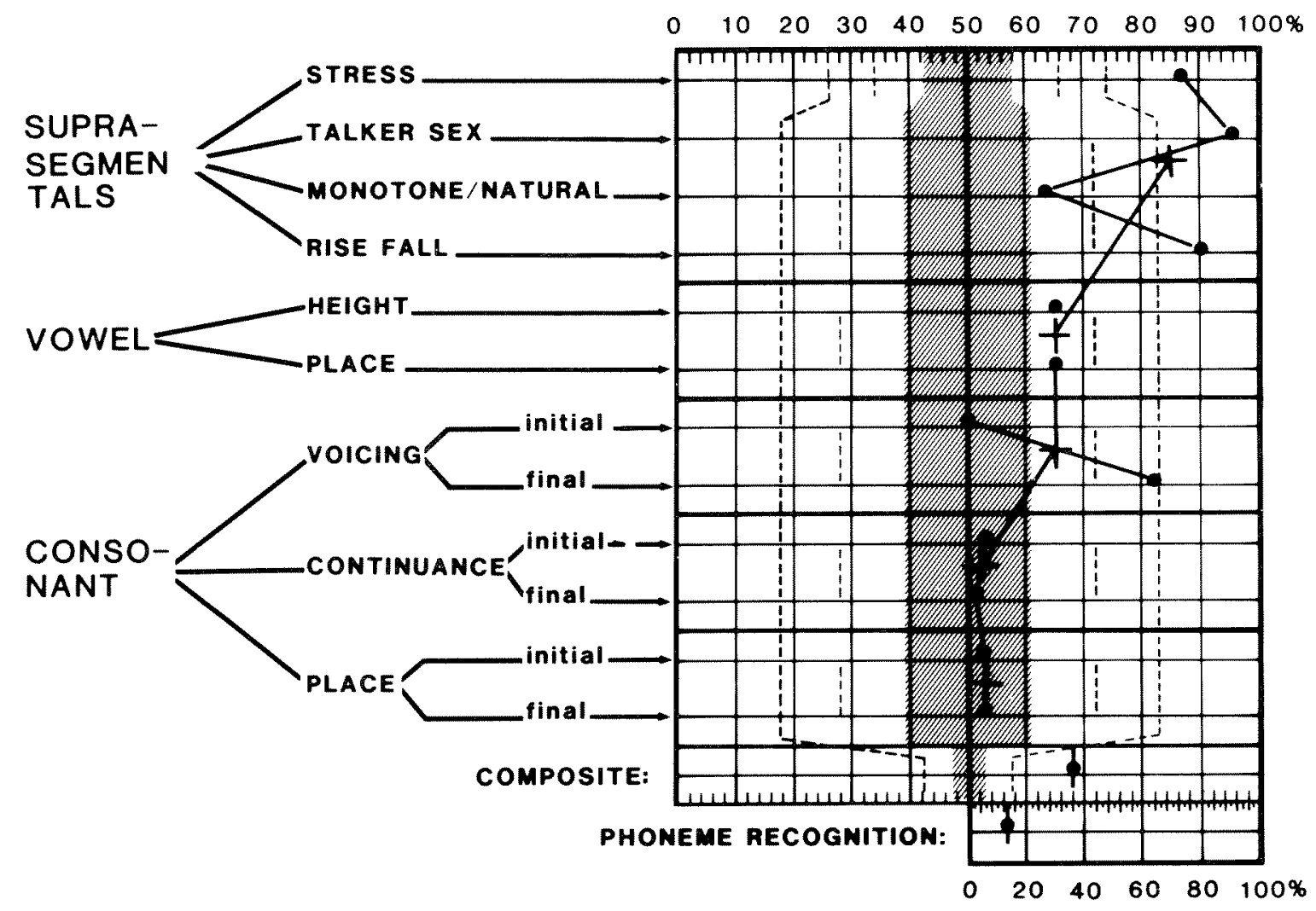

Figure 13.

Mean Speech Pattern Contrast test scores for eight CI patients. The shaded area represents chance performance.

Dots represent individual subtest mean scores; plus signs represent the combination of two subtests.

device has been shown to provide significantly clinical benefit to a large number of profoundly deaf adults. However, one must keep in mind that whereas cochlear implant patients have experienced total deafness prior to receiving the prosthesis, CEP patients may have significant residual hearing prior to tumor removal. Therefore, we might expect some difference in psychological response to these two devices.

The limited dynamic range of the CEP patients (in some cases as narrow as $4 \mathrm{~dB}$ ) indicates the need for a highly nonlinear signal-processing scheme. The major challenge lies in providing suitable compression and spectral adjustment to contain all signal peaks within comfortable loudness levels without losing important parts of the signal. This issue has not been fully addressed with either the baseband stimulator (modified hearing aid) used by the first patient until 1985 , or by the $3 \mathrm{M} /$ House processor (16-kHz amplitude-modulated signal).

Patient performance was similar with the baseband stimulator and the $3 \mathrm{M} / \mathrm{House}$ processor. $\mathrm{Be}$ - cause of the constant $16-\mathrm{kHz}$ signal, the use of the $3 \mathrm{M} /$ House processor allows for better control over the applied charge density levels; and, by enabling efficient transmission of the signal across the skin to an implanted coil, it offers an alternative to the percutaneous plug interface. This stimulation scheme has served as a temporary solution until a more optimal processor can be provided. Preliminary work to develop a digital signal processor that will provide appropriate compression, spectral balancing, and filtering, is under way. Pyschophysical testing protocols are under preparation and include differential thresholds, pulse rate identification, pulsatile loudness functions, and gap detection.

For a typical patient on an average day, impedance will decrease by about 30 percent from threshold to ULL at $250 \mathrm{~Hz}$; and by about 5 percent at $16 \mathrm{kHz}$. The dynamic nature of the impedance is subject to variations. Preliminary data analysis shows no direct relation between dynamic impedance changes and current at threshold in any of the patients. The difference in thresholds across patients (Figure 7) 
suggests varying amounts of fibrosis in the area surrounding the electrode plates.

Variations in electrical and perceptual parameters across patients indicate the need for a flexible signal processor that can be adapted to the needs of individual patients. The monopolar testing results obtained with two of the patients show some promise for the possibility of utilizing multielectrode arrays in the future. Long-term goals include the development of a multichannel/multielectrode system.

Safety is an obvious concern when stimulating in the brain stem. Nonauditory sensations have been minimal. Patient MD gradually lost all auditory percepts and began experiencing tingling sensations in her leg concurrently with electrical stimulation from her first electrode system in 1979. Those sensations did not reoccur following surgical revision in 1981. Patient SS experienced vertigo accompanied by eyes-open nystagmus for the first week after surgery in conjunction with electrical stimulation. Those reactions have not since been experienced. With the exception of infections at the site of the percutaneous pedestal, no medical complications have occurred to date.

These preliminary findings suggest that chronic electrical stimulation of the cochlear nuclear complex in the brain stem is feasible in humans. The central electroauditory prosthesis is proving to be a viable alternative for totally deaf individuals who cannot benefit from cochlear implants. A long-term clinical trials program is under way.

\section{Acknowledgments}

The authors wish to acknowledge the following individuals: Edwin M. Monsell, M.D., Ph.D., and Leonid I. Terr, Ph.D., for the anatomical research that resulted in the descriptions used in this paper; Janet Stoeckert for assistance in statistical analysis of the SPAC data; Anna Maggio for graphic artwork of the audiological data; Ron Campise for photographing the illustrations; Karen I. Berliner, Ph.D., and Diane Foster Knudsen for editorial assistance; and Deborah Minette for preparation of the manuscript.

\section{APPENDIX}

Potential problems exist in the electrical stimulation of the cochlear nuclear complex. These include neural injury, electrical charge spread, and electrochemical reactions. These problems are minimized by the use of bipolar-biphasic current and by limiting the charge density to safe levels. Pudenz et al. (12) reported "safe" stimulation of neural tissue at a charge density (QD/ph) of $48.7 \mu \mathrm{C} / \mathrm{cm}^{2} /$ phase. Yuen et al. (15) showed "minimal and mild neural damage" of neural tissue on the parietal cortex of cats at $40 \mu \mathrm{C} / \mathrm{cm}^{2} /$ phase. HEI engineers have designated $17 \mu \mathrm{C} / \mathrm{cm}^{2} /$ phase as the upper limit for safe delivery of charge to the CEP electrode without the risk of damage to neural tissue. This limit provides a safety margin as close as possible to 100 percent with some additional compensation for possible variations in electrode area. The maximum charge with sinusoid stimulation can be calculated by integrating the peak current under the curve as follows:

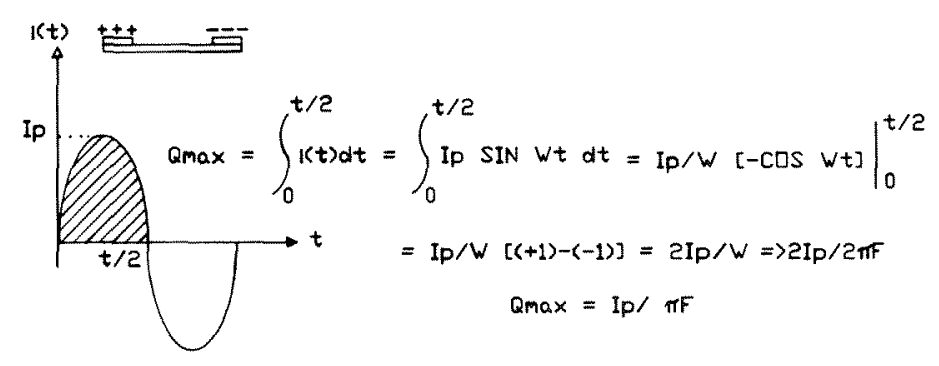

Charge density for the case of RMS current values is:

$$
\begin{aligned}
& \text { Irms }=\operatorname{Ip} / \sqrt{2} \quad \text { then Ip }=\sqrt{2} \text { Irms } \\
& \text { and by substitution } \\
& \text { Qmax }=\sqrt{2} \text { Irms } / \pi F=.45(\text { Irms } / F) \\
& \text { now } Q D=\text { Qmax/unit Area } \\
& \text { therefore } \\
& Q D=(\operatorname{Irms} / F)(.45) / \text { Area }
\end{aligned}
$$

The maximum rms current that can be delivered to the electrode during patient testing is calculated from the maximum allowable charge density. Such calculations also depend on the frequency of the 
sinusoidal stimuli and the geometric area of the electrode $\left(0.019 \mathrm{~cm}^{2}\right)$.

$$
\text { Irms }=\frac{\mathrm{QD} \times \mathrm{AREA}}{0.45} \times \mathrm{F}
$$

Where:

$$
\begin{aligned}
\mathrm{QD}= & \text { charge density in microCoulombs/phase/ } \\
& \mathrm{cm}^{2}(17 \mu \mathrm{C})
\end{aligned}
$$

\section{REFERENCES}

1. BoOTHRoyd A: Auditory perception of speech contrasts by subjects with sensorineural hearing loss. J Speech Hear Res 27:134-144, 1984.

2. BoOTHROYD A: Measurement of speech feature perception in subjects with limited hearing: A speech pattern contrast (SPAC) test. Abstracts of the Acoustical Society of America, Austin, TX, 1985.

3. Bullara la, Agnew WF, Yuen TGH, Jacques S, PudEnz RH: Evaluation of electrode array material for neural prostheses. Neurosurg 5:681-686, 1979.

4. Edgerton BJ, House WF, Hitselberger W: Hearing by cochlear nucleus stimulation in humans. Ann Otol Rhinol Laryngol, Suppl 91 91:117-124, 1982.

5. Edgerton BJ, Prietto A, Danhauer JL: Cochlear implant patient performance on the MAC battery. Otolaryng Clin N Am 16:267-280, 1983.

6. EISENBERG LS AND Berliner KI: Rehabilitative procedures for the cochlear implant patient. I Acad Rehab Audiol 16:104-113, 1983.

7. ERBER NP AND AlencewiCZ CM: Audiologic evaluation of deaf children. J Speech Hear Dis 41:256-267, 1976.

8. Fretz RJ AND Fravel RP: Design and function: A physical and electrical description of the $3 \mathrm{M} / \mathrm{House}$ cochlear implant system. Ear and Hearing, Suppl 6:14S-19S, 1985.

$$
I=\text { current in microAmperes rms }
$$$$
F=\text { frequency of stimuli in Hertz }
$$
AREA $=$ the geometric area of the electrode in $\mathrm{cm}^{2}$

Driving the load at different frequencies, the internal impedance can be calculated by dividing the applied rms voltage by the rms current drawn by the load (Ohms Law).

9. House WF AND LuetJe CM (eds): Acoustic Tumors. Baltimore: University Park Press, 1979.

10. Morgan DE, Dirks DD, Bower DR: Suggested threshold sound pressure levels for frequency-modulated (warble) tones in the sound field. $J$ Speech Hear Dis 44:37-54, 1979.

11. Owens E, Kessler D, Telleen C, Schubert E: The minimal auditory capabilities test (MAC) battery. Hear Aid J 34:9-34, 1981.

12. Pudenz RH, Agnew WF, Yuen TGH, Bullara LA: Electrical stimulation of brain-light and electron microscopy studies. In Hambrecht FT, Reswick JB (eds): Functional Electrical Stimulation. New York: Marcel Dekker, Inc., 1977.

13. TERR LI AND Edgerton BJ: Three-dimensional reconstruction of the cochlear nuclear complex in humans. Arch Otolaryngol 111:495-501, 1985

14. Thielemeir MA, Brimacombe JA, Eisenberg LS: Audiological results with the cochlear implant. Ann Otol Rhinol Laryngol, Suppl 91 91:27-34, 1982.

15. Yuen TGH, Agnew WF, Bullara LA, JaCques S, ET AL.: Histologic evaluation of neural damage from electrical stimulation: Considerations for selection of parameters for clinical application. Neurosurg 9:292-299, 1981. 